\title{
Developmental ability of cloned embryos from neural stem cells
}

\author{
Eiji Mizutani ${ }^{1}{ }^{2}$, Hiroshi Ohta ${ }^{1}$, Satoshi Kishigami ${ }^{1}$, Nguyen Van Thuan ${ }^{1}$, Takafusa Hikichi ${ }^{1}$, \\ Sayaka Wakayama ${ }^{1,3}$, Mitsuko Kosaka ${ }^{4}$, Eimei Sato ${ }^{2}$ and Teruhiko Wakayama ${ }^{1}$ \\ ${ }^{1}$ Laboratory for Genomic Reprogramming, Center for Developmental Biology, RIKEN, Kobe, Japan, ${ }^{2}$ Laboratory of \\ Animal Reproduction, Graduate School of Agricultural Science, Tohoku University, Sendai, Japan, ${ }^{3}$ Department of \\ Life Science, Graduate School of Science and Technology, Kobe University, Kobe 657-8501, Japan and ${ }^{4}$ Research Unit \\ for Cell Plasticity, Center for Developmental Biology, RIKEN, Kobe, Japan
}

Correspondence should be addressed to E Mizutani; Email: mizutani@cdb.riken.jp

\begin{abstract}
The success rate is generally higher when cloning mice from embryonic stem (ES) cell nuclei than from somatic cell nuclei, suggesting that the embryonic nature or the undifferentiated state of the donor cell increases cloning efficiency. We assessed the developmental ability of cloned embryos derived from cultured neural stem cell (NSC) nuclei and compared the success rate with that of embryos cloned from other donor cells such as differentiated NSCs, cumulus cells, Sertoli cells and ES cells in the mouse. The transfer of two-cell cloned embryos derived from cultured NSC nuclei into surrogate mothers produced five live cloned mice. However, the success rate $(0.5 \%)$ was higher in embryos cloned from cultured NSC nuclei than from differentiated NSCs $(0 \%)$, but lower than that obtained by cloning mice from other cell nuclei (2.2-3.5\%). Although the in vitro developmental potential to the two-cell stage of the cloned embryos derived from NSC nuclei $(73 \%)$ was similar to that of the cloned embryos derived from other somatic cell nuclei (e.g., $85 \%$ in Sertoli cells and $75 \%$ in cumulus cells), the developmental rate to the morula-blastocyst stage was only $7 \%$. This rate is remarkably lower than that produced from other somatic cells (e.g., $50 \%$ in Sertoli cells and $54 \%$ in cumulus cells). These results indicate that the undifferentiated state of neural cells does not enhance the cloning efficiency in mice and that the arrest point for in vitro development of cloned embryos depends on the donor cell type.
\end{abstract}

Reproduction (2006) 132 849-857

\section{Introduction}

The recent development of nuclear transfer techniques has enabled researchers to generate cloned animals from somatic cells in a number of species. However, the success rates of animal cloning from adult somatic cells are consistently low. Although we have tried to improve the success rate of cloning in the mouse, usually fewer than $3 \%$ of the cloned embryos develop to term when somatic cells are used as donors (Wakayama et al. 1998, 2003, 2005a, Wakayama \& Yanagimachi 1999, 2001). We have recently improved the success rate using trichostatin A during the oocyte-activation process, although the success rate remains low (Kishigami et al. 2006).

Although some believe that embryonic stem (ES) cells are not much better as the donor cell for nuclear transfer (Oback \& Wells 2002), the success rate for producing cloned mice from several ES cell lines appears to be higher (12.3-33\%) than the rates for other differentiated donor cells (Wakayama et al. 1999, Rideout et al. 2000, Jeanisch et al. 2002). Inoue et al. (2005) have also generated cloned mice from terminally differentiated cells, but the success rates were low (1.1-1.6\%). These results suggest that the undifferentiated state of the donor cells may increase the birth rate of cloned animals. Cheong et al. (1993) and Hiiragi \& Solter (2005) found that the developmental stage of donor embryos affects the cloning efficiency. In their results, cloned embryos receiving early-developmental-stage embryo nuclei developed to term, but those receiving late-stage embryo nuclei had seriously limited development. Their results also suggest that using undifferentiated donor nuclei is effective for generating cloned animals. Yamazaki et al. (2001) also reported that cloned embryos develop to term with high efficiency $(6 \%)$ in freshly isolated fetal immature neural cells transferred into enucleated oocytes. Thus, the undifferentiated state of the donor cell, such as tissue-specific stem cells, may increase the animal cloning efficiency even if the cell is derived from a somatic cell lineage. Consistent with this hypothesis, Inoue et al. (2006) also used adult hematopoietic stem cells (HSCs) in the mouse. Although they generated 
cloned offspring, the birth rates $(0-0.7 \%)$ were the lowest among the clones tested (cumulus, immature Sertoli, and fibroblast cells). It is still unclear whether the lower birthrate in HSCs is caused by HSC-specific or more general somatic stem cell properties. Investigating other somatic stem cells used in nuclear transfer may help resolve this issue.

Recently, many types of somatic stem cells have been identified in hematopoietic (Weissman 2000), hepatic (Alison \& Sarraf 1998), epidermal (Watt 1998), gastrointestinal (Potten 1998), muscle (Jiang et al. 2002b), bonemarrow (Fridenshtein 1982, Jiang et al. 2002a, 2002b), and neural tissues (Gage 2000, Jiang et al. 2002b). In the brain, the subventricular zone is the primary source of proliferating cells that replenish olfactory interneurons and glial cells (Peretto et al. 1999, Brazel et al. 2003). Neural stem cells (NSCs) can be cultured over the long term and are able to self-renew and differentiate into neurons, astrocytes, and oligodendrocytes when exposed to cytokines in vitro (Reynolds \& Weiss 1992, 1996). Thus, the NSC is one type of well-defined somatic stem cell that can proliferate and differentiate in vitro. This multipotent developmental characteristic of NSCs may increase mice cloning efficiency, if the undifferentiated state of the donor cells affects the success rate, as observed with ES cell donors. The proliferative ability of NSCs may provide an opportunity to apply the cloning technique to the agricultural field or for basic research, because ES cells are the only cell type presently identified as a nuclear donor for mouse cloning with high efficiency. We assessed the developmental potential of cloned mouse embryos from in vitro cultured NSCs and compared this with the cloning efficiency for differentiated neural derivatives, ES cells, and commonly used somatic cell types.

\section{Materials and Methods}

\section{Mice}

All mice used in this study were purchased from Shizuoka Laboratory Animal Center (Hamamatsu, Japan) or bred in our mouse colony. All animal experiments conformed to the Guidelines for the Care and Use of Laboratory Animals and were approved by the Institutional Committee for Laboratory Animal Experimentation (RIKEN Kobe Institute).

\section{NSC collection}

On days 1-4, $129 \times$ B6 F1 (129B6F1) male mice were killed, the craniums were removed with fine scissors, and the brains were excised. The subventricular zone of the brain was dissected and minced with fine scissors in PBS. The tissue was then placed in PBS containing $0.05 \%$ trypsin and $0.1 \mathrm{mM}$ EDTA and incubated for $15 \mathrm{~min}$ at $37{ }^{\circ} \mathrm{C}$. After the addition of a half volume of Dulbecco's modified Eagle's medium (DMEM,
Sigma-Aldrich) containing 10\% fetal calf serum (FCS), the cell suspension was passed through a nylon mesh (30 $\mu \mathrm{m}$ pore size) to remove the remaining large solid material. The cell suspension was washed twice with DMEM, and the cells were resuspended in NSC culture medium (NeuroCult NSC Basal Medium; StemCell Technologies, Inc., Vancouver, BC, Canada) containing NeuroCult NSC Proliferation Supplements (StemCell Technologies, Inc.) and $20 \mathrm{ng} / \mathrm{ml}$ recombinant human epidermal growth factor.

\section{NSC culture and preparation of donor NSCS}

NSCs were cultured as neurospheres, as described previously (Kim \& Morshead 2003). The dishes were incubated on a gyratory shaker in a $\mathrm{CO}_{2}$ incubator. After 4 days of culture, colonies were observed as spheres. For nuclear transfer and passage, spheres were collected and a single-cell suspension was obtained by drawing the spheres through a pipette. The cell suspensions were kept at $4{ }^{\circ} \mathrm{C}$ until injection or were resuspended in NSC culture medium and the culture continued. Cells were stained with Trypan blue at each passage of NSCs, and nearly all cells survived after trituration of the neurospheres. In this study, NSCs that were passaged not more than three times were used as donor cells for nuclear transfer. To obtain differentiated NSCs, NSCs were collected and cultured as described earlier. For in vitro differentiation, the portions of the isolated NSCs were cultured on poly-D-lysine/laminin-coated glass plates in NeuroCult NSC Basal Medium containing NeuroCult NSC Differentiation Supplements for 10-14 days. After culture, the cells were treated with $0.05 \%$ trypsin and $0.1 \mathrm{mM}$ EDTA to detach them from the culture dish. After the addition of a half volume of DMEM containing $10 \%$ FCS, the cell suspension was washed twice with DMEM and used for nuclear transfer. The cell suspensions were kept at $4{ }^{\circ} \mathrm{C}$ until injection. Owing to the difficulty of nuclear transfer, differentiated and undifferentiated donor cells were prepared and used on different days.

\section{Immunostaining}

To confirm that the cells were undifferentiated, the neurospheres were stained to identify them as undifferentiated neural cells. The primary antibodies were mouse monoclonal anti-Nestin (CHEMICON International, Inc., Temecula, CA, USA; Duittoz \& Hevor 2001) as the NSC marker and mouse monoclonal antiTuJ (StemCell Technologies, Inc.; Sullivan 1988) as a marker of the early stage of neural differentiation in neurons of the central and peripheral nervous systems. The secondary antibodies were Alexa Fluor 488-labeled goat anti-mouse IgG and Alexa Fluor 568-labeled goat anti-mouse IgG (both from Molecular Probes, Inc., Eugene, OR, USA). 
Some of the spheres were triturated to produce cell suspensions of each type of sphere. A portion of the cell suspensions was stained with Nestin antibody to estimate the percentage of Nestin-positive cells in the spheres. The other portions were cultured on poly-D-lysine/laminincoated glass plates in NeuroCult NSC Basal Medium containing NeuroCult NSC Differentiation Supplements. After 10 days of culture, the cells were stained to confirm their ability to differentiate. The primary antibodies were Nestin, TuJ, mouse monoclonal anti-glial fibrillary acidic protein (GFAP, CHEMICON International, Inc.; Debus et al. 1983), and mouse monoclonal anti-oligodendrocyte marker O4 (CHEMICON International, Inc.; Sommer \& Schachner 1981). The secondary antibodies were Alexa Fluor 488-labeled goat anti-mouse IgG, Alexa Fluor 568-labeled goat anti-mouse IgG, and Alexa Fluor 568-labeled goat anti-mouse IgM (all from Molecular Probes, Inc.).

\section{Preparation of immature Sertoli cells for nuclear transfer}

Immature Sertoli cells were isolated from the testes of 129B6F1 mice (3-7 days old) as described previously (Ogura et al. 2000) with minor modification. Briefly, the testes were decapsulated in PBS and the seminiferous tubules were incubated in Hanks' solution containing $0.05 \%$ trypsin and $0.1 \mathrm{mM}$ EDTA for $15 \mathrm{~min}$ at $37{ }^{\circ} \mathrm{C}$. After the cells were separated, a half volume of DMEM containing $10 \%$ FCS was added and the cell suspension was washed with DMEM three times. The cell suspension was kept on ice until injection.

\section{Preparation of cumulus cells for nuclear transfer}

Cumulus cells from 129B6F1 female mice were also used as donor cells. The 129B6F1 females (8-12 weeks old) were induced to superovulate with 5 iu equine chorionic gonadotropin (eCG), followed by 5 iu human chorionic gonadotropin (hCG) $48 \mathrm{~h}$ later. Cumulus-oocyte complexes were collected in Hepes-buffered ChatotZiomek-Bavister (CZB) medium $16 \mathrm{~h}$ after hCG injection, and the cumulus cells were dispersed by $0.1 \%$ hyaluronidase. Collected donor cells were placed into HepesCZB medium containing $12 \%$ polyvinylpyrolidone and kept on ice until injection.

\section{Preparation of ES cells for nuclear transfer}

The 129B6F1 male ES cell line was established from the blastocyst, collected from a 129/Sv female mated with a C57BL/6 male in our laboratory and used within 4-5 passages. The cells were cultured in knockout DMEM (Invitrogen Corp.) supplemented with 20\% heat-inactivated FCS, 1000 units/ml leukemia inhibitory factor (Invitrogen Corp.), and the following reagents (Specialty
Media, Lavallette, NJ, USA): $1 \%$ penicillin-streptomycin, $1 \%$ L-glutamine, $1 \%$ non-essential amino acids, $1 \%$ nucleosides, and $1 \% \beta$-mercaptoethanol. On the day of nuclear transfer, cells were treated with $0.05 \%$ trypsin and $0.1 \mathrm{mM}$ EDTA to detach them from the culture dish. After the addition of a half volume of DMEM containing $10 \%$ FCS, the cell suspension was washed twice with DMEM and used for nuclear transfer. The cell suspensions were kept on ice until injection.

\section{BrdU staining}

Neurospheres, differentiated neural cells, cumulus cells, and ES cells were cultured for $1 \mathrm{~h}$ in each culture medium containing $10 \mu \mathrm{M}$ bromodeoxyuridine (BrdU, BD Biosciences, San Jose, CA, USA). After BrdU labeling, spheres were triturated by pipette, the differentiated neural cells and ES cells were trypsinized, and the cumulus cells were treated with hyaluronidase to free single cells. Each cell type was attached onto glass slides and the proportion of BrdU-positive cells was determined using a BrdU in situ Detection Kit (BD Biosciences).

\section{Preparation of oocytes for nuclear transfer}

Mature oocytes were collected from the oviducts of 8- to 12-week-old BDF1 females that had been induced to superovulate by injection of eCG and hCG, as described earlier. Oocytes were collected from their oviducts about $16 \mathrm{~h}$ after hCG injection and placed in Hepes-buffered CZB medium containing $0.1 \%$ hyaluronidase. The denuded oocytes were then placed in fresh CZB medium and cultured until use.

\section{Enucleation of oocytes}

Oocytes were transferred to a droplet (about $10 \mu \mathrm{l}$ ) of Hepes-CZB containing $5 \mu \mathrm{g} / \mathrm{ml}$ cytochalasin B that had been placed under oil in the operation chamber of a microscope stage. The oocyte was held with an oocyteholding pipette and its zona pellucida was perforated by applying several piezoelectric pulses with the tip of an enucleation pipette (Wakayama et al. 1998). The metaphase II chromosome spindle complex, distinguished as a translucent spot in the ooplasm, was drawn into the pipette with a small amount of accompanying ooplasm and pulled gently away from the oocyte until the stretched cytoplasmic bridge was pinched off.

\section{Injection of donor cell nuclei into enucleated oocytes}

A donor cell was drawn in and out of the injection pipette until the plasma membrane was disrupted. In some cases, a few piezoelectric pulses were applied to break the membranes. The donor nuclei were injected into enucleated oocytes as described previously 
(Wakayama et al. 1998). Briefly, the zona pellucida of the enucleated oocyte was perforated by applying several piezoelectric pulses, and the membrane of the oocyte was perforated with a few more piezoelectric pulses. The donor nucleus was then inserted into the ooplasm. After the donor nucleus was injected, the reconstructed oocyte was transferred into a droplet of CZB medium and incubated at $37{ }^{\circ} \mathrm{C}$ under $5 \% \mathrm{CO}_{2}$.

\section{Activation of reconstructed oocytes}

Reconstructed oocytes were activated by incubation at $37{ }^{\circ} \mathrm{C}$ for $6 \mathrm{~h}$ in $\mathrm{Ca}^{2+}$-free CZB containing $10 \mathrm{mM} \mathrm{Sr}^{2+}$ and $5 \mu \mathrm{g} / \mathrm{ml}$ cytochalasin B. After activation, the oocytes were cultured in CZB medium at $37{ }^{\circ} \mathrm{C}$ under $5 \% \mathrm{CO}_{2}$ until the two-cell stage at $24 \mathrm{~h}$ for embryo transfer or until the morula-blastocyst stage for observation of in vitro development at $72 \mathrm{~h}$.

\section{Embryo transfer}

Activated reconstructed oocytes were cultured for 24-30 $\mathrm{h}$ in CZB medium until the two-cell stage. The embryos were then transferred to the oviducts of surrogate ICR female mice on day 1 of pseudopregnancy.

\section{Statistical analyses}

Outcomes were evaluated using $\chi^{2}$-tests. $P<0.05$ was accepted as significant.

\section{Results}

\section{Characterization of neural stem cells prepared from neurospheres}

After 4 days of culture, NSCs proliferated as neurospheres (Fig. 1). All neurospheres were positive for the undifferentiated neural cell marker, Nestin (Fig. $1 A, A^{\prime}, A^{\prime \prime}$ ), but were negative for $T u J$, the differentiated neural cell marker (Fig. 1B, $\mathrm{B}^{\prime}, \mathrm{B}^{\prime \prime}$ ). These results indicate that these spheres were in an undifferentiated state. Some of these neurospheres were then triturated until they became single cells, which were stained with Nestin antibody; 539 out of $624(86.4 \%)$ of the single cells constituting spheres were positive for Nestin (Fig. 1C, $C^{\prime}$ ). This result indicated that most cells from the spheres used as donor cells in the nuclear transfer were in the undifferentiated state. The single-cell suspensions from neurospheres were cultured on poly-D-lysine/ laminin-coated culture slides to confirm their ability to differentiate. After 10 days of culture, morphologically differentiated neural cells were observed. These cells were negative for Nestin antibody (Fig. 2A), and positive for TuJ antibody (Fig. 2B), glial marker GFAP (Fig. 2C), and oligodendrocyte marker O4 (Fig. 2D). These results indicate that the stem cell property of neural cells is maintained in vitro by the spherical culture method, as described previously (Kim \& Morshead 2003).
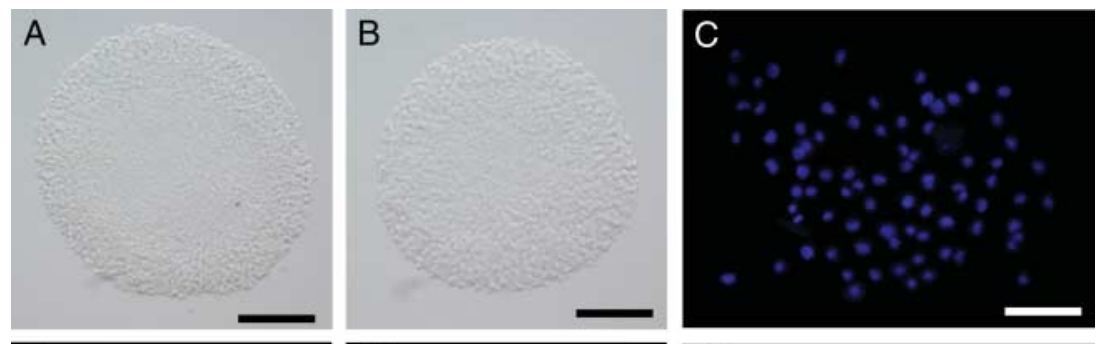
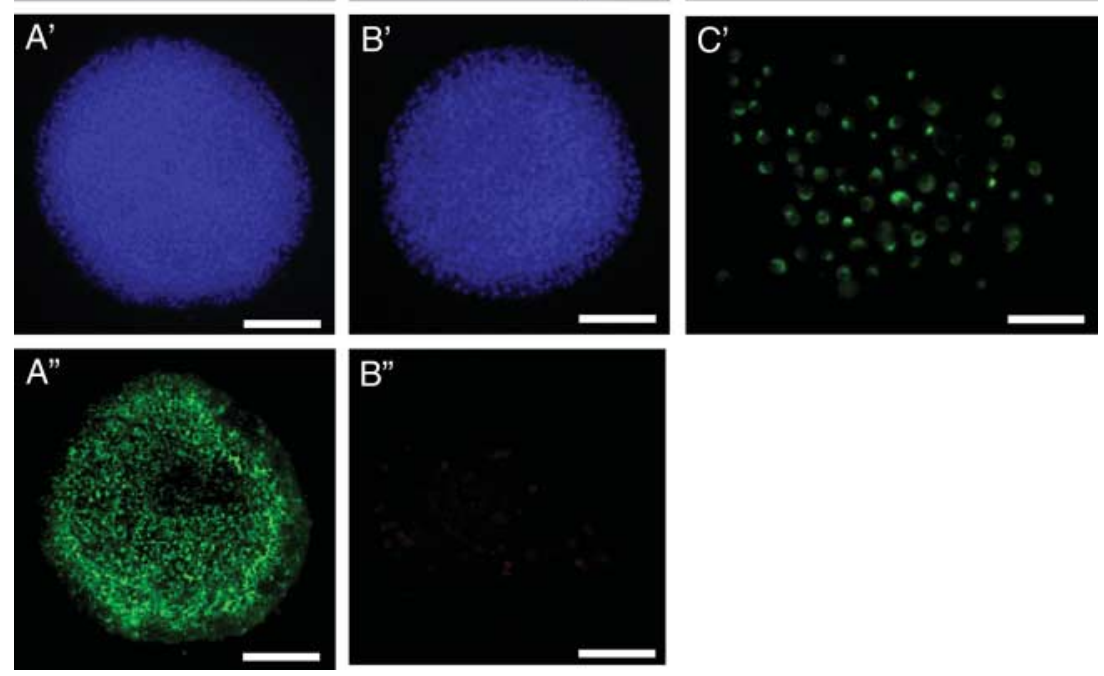

Reproduction (2006) 132 849-857
Figure 1 Immunofluorescent staining of neurospheres. Neurospheres were positive for the neural stem cell marker, Nestin $\left(A, A^{\prime}, A^{\prime \prime}\right)$, and were negative for the mature neural cell marker, TuJ (B, B', B ${ }^{\prime \prime}$ ). Neurospheres contained $86.4 \%$ Nestin-positive cells $\left(C, C^{\prime}\right)$. A: A bright field image of neurospheres stained with Nestin antibody. $A^{\prime}:$ 4',6-diamino-2-phenylindole (DAPI) staining. $A^{\prime \prime}$ : Nestin antibody, a neural stem cell marker. B: a bright field image of neurosphere stained with TuJ antibody. B': DAPI. B": TuJ. C: DAPI staining of single cells from neurospheres. $C^{\prime}$ : Nestin antibody. Scale bar $=A, A^{\prime}, A^{\prime \prime}, B, B^{\prime}$, $\mathrm{B}^{\prime \prime}=100 \mu \mathrm{m}, \mathrm{C}, \mathrm{C}^{\prime}=50 \mu \mathrm{m}$. 

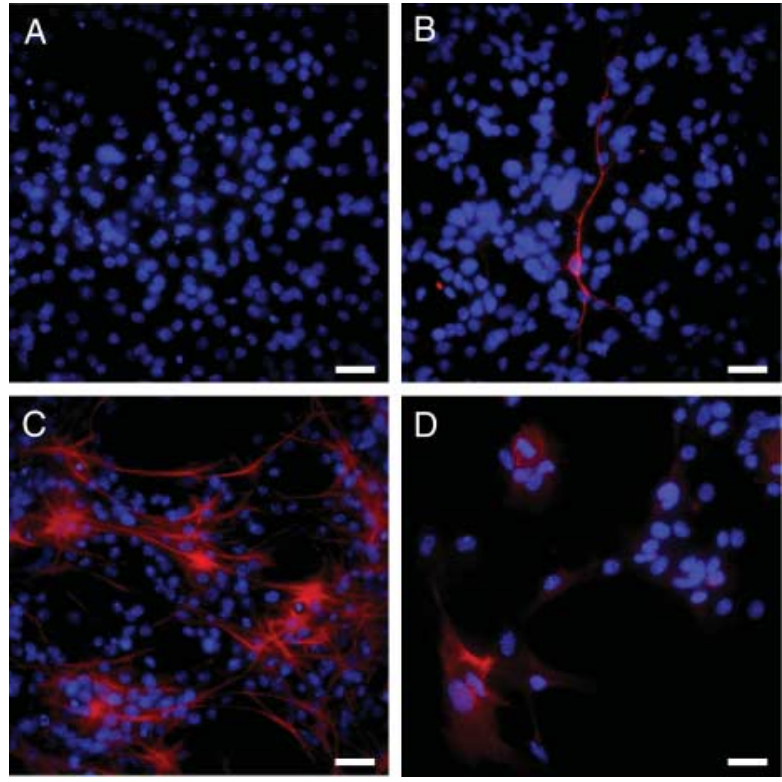

Figure 2 Immunofluorescent staining of differentiated neural cells from neurospheres. Immunofluorescent staining of single cells from neurospheres cultured on poly-D-lysine/laminin-coated glass plates for 10 days. DAPI (blue); Nestin (green); TuJ, anti-glial fibrillary acidic protein (GFAP), and anti-oligodendrocyte marker O4 (all red). A: Nestin, B: TuJ, C: GFAP antibody, and D: O4. Scale bar $=30 \mu \mathrm{m}$.

\section{In vivo development of reconstructed embryos after transfer of NSCs into enucleated oocytes}

To investigate whether cloned mice can be produced efficiently using NSCs as donor cells, the in vivo development of reconstructed embryos that received NSCs was compared with the development of embryos from other donor cells, such as differentiated NSCs, immature Sertoli cells, cumulus cells, and ES cells. The developmental rate was similar in embryos that had received NSCs and other somatic cells, differentiated NSCs, Sertoli cells and cumulus cells, at least up to the two-cell stage $(72 \%$ for NSCs, $78 \%$ for differentiated NSCs, $78 \%$ for Sertoli cells, and $83 \%$ for cumulus cells; Table 1). The cloning success rates did not differ between NSCs and differentiated NSCs, but the survival rate of the cloned fetuses differed. After embryo transfer, five live cloned mice were obtained from reconstructed embryos that had received NSCs. All pups appeared normal, and their fertility was confirmed by mating, indicating that the NSCs have full-term developmental ability following somatic cell nuclear transfer. In contrast, although $77.8 \%$ of cloned embryos from differentiated NSCs cleaved, and $1 \%$ developed to term in the uterus of surrogate mothers, all these offspring were dead at, or died soon after, birth. Although the cloned mice were born successfully from NSC nuclei, the birth rate was significantly lower $(0.5 \%)$ than the rate in mice cloned from other donor cells $(2.2 \%$ in Sertoli cells, $2.7 \%$ in cumulus cells, and 3.5\% in ES cells; Table 1).

\section{In vitro development of reconstructed embryos after transfer of NSCs into enucleated oocytes}

To examine the cause of the low birth rate of cloned mice using NSCs, the reconstructed embryos were cultured and their developmental ability was assessed in vitro. The pronuclear formation rates of reconstructed embryos were very high $(>75 \%)$ regardless of the donor cell type (Table 2). After the pronuclear stage, the in vitro developmental potential of cloned embryos derived from differentiated somatic cell nuclei decreased gradually, and $50 \%$ of embryos reached the blastocyst stage (Table 2 and Fig. 3). The developmental behavior of differentiated NSCs was similar to that with differentiated somatic cell nuclei: $61 \%$ of reconstructed embryos cleaved, $42 \%$ of these reached the four-cell stage, and $29 \%$ developed to the morula-blastocyst stage (Table 2).

The rate of development to the two-cell stage was significantly lower in ES cell donors $(37 \%)$ than in somatic donor cell types, but most of the first-cleavage embryos developed into blastocysts (82\%; Table 2). In contrast, culturing cloned embryos derived from NSC nuclei produced similar rates of development to the twocell stage $(73 \%)$ as that achieved in the cloned embryos derived from somatic cell nuclei. However, the ability of cloned embryos derived from NSC nuclei to develop to the four-cell stage was very low (23\%), and only $10 \%$ of two-cells developed to the morula-blastocyst stage (Table 2). Thus, cloned embryos from NSCs showed in vitro developmental arrest between the two-cell and the four-cell stages (Fig. 3), perhaps contributing greatly

Table 1 Full-term development of transferred two-cell stage cloned embryos from neural stem cell (NSC), differentiated NSC, Sertoli cell, cumulus cell, and ES cell nuclei.

\begin{tabular}{|c|c|c|c|c|c|c|}
\hline Type of donor cell & $\begin{array}{l}\text { No. of oocytes } \\
\text { injected }\end{array}$ & pn $(\%)$ & $\begin{array}{l}\text { No. of embryos } \\
\text { that developed to } \\
\text { two-cell stage }(\%)^{\mathrm{a}}\end{array}$ & $\begin{array}{l}\text { No. of embryos } \\
\text { transferred }\end{array}$ & $\begin{array}{c}\text { No. of offspring } \\
\text { born }(\%)^{b}\end{array}$ & $\begin{array}{l}\text { No. of viable } \\
\text { offspring }(\%)^{b}\end{array}$ \\
\hline NSC & 1887 & $1503(79.7)^{*}$ & $1079(71.8)^{*}$ & 1072 & $5(0.5)^{*}$ & $5(0.5)^{*}$ \\
\hline Differentiated NSC & 271 & $239(88.2)^{*,+}$ & $186(77.8)^{*}$ & 186 & $2(1.1)^{*,+}$ & $0(0)^{*}$ \\
\hline Sertoli & 686 & $581(84.7)^{*,+}$ & $451(77.6)^{*}$ & 451 & - & $10(2.2)^{\dagger}$ \\
\hline Cumulus & 573 & $529(92.3)^{\dagger, \neq}$ & $440(83.2)^{*}$ & 440 & $15(3.4)^{\dagger, \neq}$ & $12(2.7)^{+}$ \\
\hline ES & 569 & $541(95.1)^{t, \neq}$ & $198(36.6)^{\dagger}$ & 198 & $10(5.0)^{\ddagger}$ & $7(3.5)^{\dagger}$ \\
\hline
\end{tabular}

* vs + , * vs $\neq$, and + vs $\neq ; P<0.05$.

aPercentages relative to the number of pronuclear formation (pn). ${ }^{b}$ Percentages relative to the number of embryos transferred. 
Table 2 In vitro development of cloned embryos from neural stem cell (NSC), differentiated NSC, Sertoli cells, cumulus cells, and ES cells.

\begin{tabular}{|c|c|c|c|c|c|}
\hline \multirow[b]{2}{*}{ Type of donor cell } & \multirow[b]{2}{*}{$\begin{array}{l}\text { No. of oocytes } \\
\text { injected }\end{array}$} & \multirow[b]{2}{*}{ pn $(\%)$} & \multicolumn{3}{|c|}{ No. of reconstructed embryos that developed to } \\
\hline & & & 2 -cell stage $(\%)^{a}$ & $4-8$-cell stage $(\%)^{\mathrm{a}}$ & $\begin{array}{l}\text { Morula-blastocyst } \\
(\%)^{\mathrm{a}}(\%)^{\mathrm{b}}\end{array}$ \\
\hline NSC & 333 & $295(88.6)^{*,+}$ & $214(72.5)^{*,+}$ & $68(23.1)^{*}$ & $21(7.1)^{*}(9.8)^{*}$ \\
\hline Differentiated NSC & 284 & $260(91.5)^{*,+}$ & $158(60.8)^{\dagger}$ & $110(42.3)^{\dagger}$ & $75(28.8)^{\dagger}(47.5)^{\dagger}$ \\
\hline Sertoli & 277 & $267(96.4)^{*}$ & $227(85.0)^{*}$ & ND & $134(50.2)^{\ddagger}(59.0)^{\dagger, \neq}$ \\
\hline Cumulus & 319 & $239(74.9)^{+}$ & $180(75.3)^{*,+}$ & $147(61.5)^{\ddagger}$ & $129(54.0)^{\ddagger}(71.7)^{\ddagger, \S}$ \\
\hline ES & 374 & $363(97.1)^{*}$ & $135(37.2)^{\ddagger}$ & $118(32.5)^{\dagger}$ & $111(30.6)^{\dagger}(82.2)^{\S}$ \\
\hline
\end{tabular}

$*$ vs $\dagger, *$ vs $\ddagger, *$ vs $\S, \dagger$ vs $\ddagger$, $†$ vs $\S$, and $\ddagger$ vs $\S ; P<0.05$.

a Percentages relative to the number of pronuclear formation (pn). ${ }^{\mathrm{b}}$ Percentages relative to the number of two-cell embryos.

to the low efficiency of cloning mice from NSCs after transferring embryos into recipients at the two-cell stage (Table 1).

\section{BrdU staining}

The cells constituting neurospheres are highly prolific, possibly because a high proportion are in the S-phase, which could interfere with subsequent development in vitro. To test this possibility, we checked the S-phase of donor cells using BrdU labeling (Fig. 4). About $20 \%$ of neurosphere cells were positive for BrdU staining. In contrast, almost all cells derived from differentiated neural cells and cumulus cells were negative for BrdU, indicating that neurospheres contain more cells in the S-phase than differentiated cells do. However, the ES cell population contained about twice as many S-phase cells as the neurospheres $(38.8 \%)$. These results indicate that the low two-cell cleavage rates of cloned embryos from ES cells might be caused by the highly proliferative property of ES cells, but that the cell cycle of the donor cells is not the only factor causing the developmental arrest of NSC-derived cloned embryos.

\section{Discussion}

The success rate for cloning mice from ES cells is relatively high compared with that for differentiated somatic cells (Wakayama et al. 1999, Rideout et al.

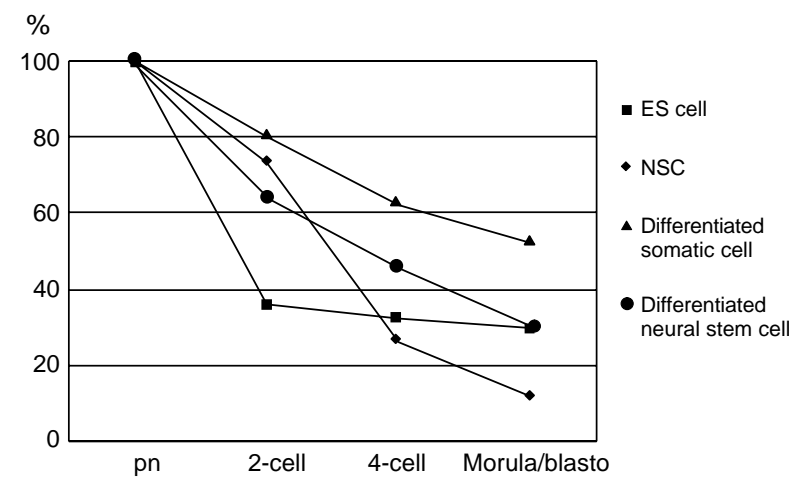

Figure 3 Differences in the in vitro development of cloned embryos between donor cell types. pn, pronuclear formation.
2000). This suggests that a cell in an undifferentiated state may be suitable as a donor cell for animal cloning. Although ES cells may be effective in nuclear transfer in mice, this process is limited in other species, where definitive ES cells have not been established. Investigation of other undifferentiated cell types, such as somatic stem cells, in nuclear transfer is important for animal cloning techniques. We have demonstrated for the first time that cloned mice can be produced from cultured postnatal NSCs. However, we were not able to improve the cloning efficiency using NSCs as the donor for nuclear transfer.

Yamazaki et al. (2001) reported that cloned mice can be generated with high efficiency (5.5\%) when fetal immature neural cells are used as donor nuclei. In contrast, differentiated neural cells appear to lose their reproductive cloning potential (Wakayama et al. 1998). To overcome the low success rate, several laboratories have used a combination of nuclear transfer with ES cells isolated from somatic cloned blastocysts (ntES cells, Wakayama et al. 2001) and tetraploid embryo complementation (Nagy et al. 1990, Eggan et al. 2001) to produce offspring indirectly from differentiated neural

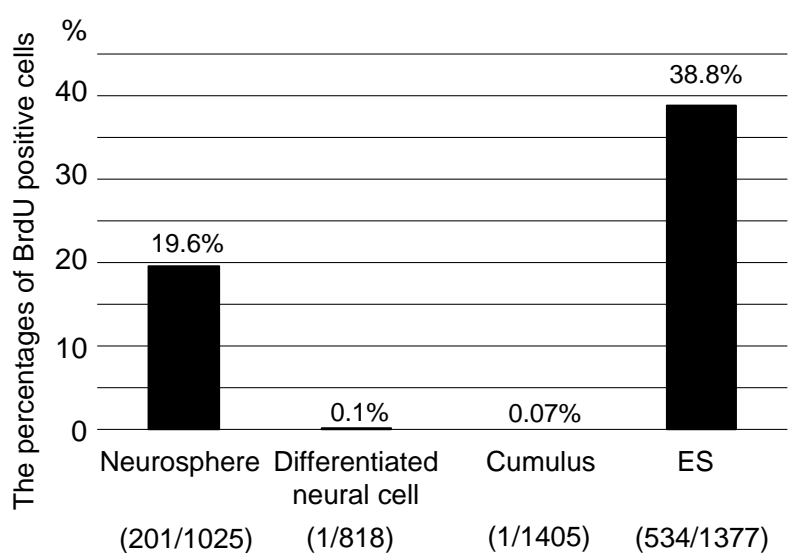

Figure 4 The percentage of BrdU-positive neurosphere cells, differentiated neural cells, cumulus cells, and ES cells. Undifferentiated cell types (neurosphere and ES cells) had relatively high proportions of cells that were positive for $\mathrm{BrdU}$ incorporation. BrdU was rarely detected in the differentiated cell types tested (differentiated neural cells and cumulus cells). 
cells (Eggan et al. 2004, Li et al. 2004). Makino et al. (2005) also produced clonal mice using the same technique and found developmental abnormalities, such as growth retardation, a small head, incomplete rotation of the body axis, open anterior neuropore, undulated neural tube closure, and asymmetrically sized somatic pairs. We found that differentiated NSCs used for nuclear transfer produced cloned mice that could not survive, consistent with a previous report (Makino et al. 2005). However, we also found that using NSCs as donor cells produced live offspring, and all five cloned mice obtained from cultured NSCs appeared normal. The success rate in our study was lower than that in a previous study, which used fetal immature neural cells (Yamazaki et al. 2001); the differences in success rates may be related to the different donor ages of cells used in these studies. This suggests that epigenetic or genetic changes occur during neural differentiation.

The neurospheres contain NSCs and some differentiated cells, and there is no marker to identify a pure NSC population (Reynolds \& Weiss 1996). Therefore, we cannot exclude the possibility that some differentiated cells were used instead of NSCs as donor nuclei. However, the result of single-cell staining obtained from neurospheres showed that $86.4 \%$ of the cells were Nestin positive. Moreover, the developmental potential differed between cloned embryos derived from neurospheres and from differentiated NSCs, suggesting that the donor cells of the neurospheres we used were mainly undifferentiated.

Interestingly, the stage of in vitro developmental arrest of cloned embryos differed between donor cell types. The rate of in vitro development from the pronuclear stage to the two-cell stage was markedly lower in cloned embryos derived from ES cells (37\%; Table 2) than in embryos derived from other somatic cell types (61-85\%; Table 2). One reason for this lower developmental rate relates to the highly proliferative activity of ES cells, as indicated by BrdU labeling (39\% in ES cells and $<0.1 \%$ in cumulus cells and differentiated NSCs; Fig. 4). Although NSCs also showed some proliferative activity (20\% BrdU positive; Fig. 4), $73 \%$ progressed to the twocell stage (Table 2).

In embryos developing from the two-cell stage to the morula-blastocyst stage, most ES cell-derived embryos reached these stages (83\%; Fig. 3). In contrast, only $50-70 \%$ of two-cell embryos derived from somatic cells (cumulus and differentiated NSCs in Fig. 3) reached this developmental milestone. NSC-derived embryos showed characteristic developmental arrest during the transition from the two-cell to the four-cell stage, and only $7 \%$ of embryos reached the morula-blastocyst stage, in contrast to the higher proportion $(29-54 \%)$ in other cell types. Although we have no clear understanding about why the developmental arrest of derived embryos occurred during the transition from the two-cell to four-cell stage, a similar developmental arrest has been observed in HSC-derived embryos (Inoue et al. 2006). They found that the expression of histone deacetylase 1 (Hdac1), an important gene regulating epigenetic status (Schultz et al. 1999, Ma et al. 2001, Zeng \& Schultz 2005), was specifically repressed in HSC-derived embryos. Similar abnormal zygotic gene activation may have occurred in NSC-derived cloned embryos here, which might have caused the low developmental rate.

To reduce the negative effect of in vitro culture, we transferred all cloned embryos into the oviducts of surrogate mothers at the two-cell stage. Although cloned mice were born successfully from all donor cell types examined, the birth rate was significantly lower in embryos cloned from NSC nuclei $(0.5 \%)$ than in embryos cloned from Sertoli and cumulus cells (Table 1). Although $1.1 \%$ of two-cell cloned embryos from differentiated NSCs developed to term, none of the cloned mice survived: $2.2 \%$ in Sertoli cells, $2.7 \%$ in cumulus cells, and $3.5 \%$ in ES cells (Table 1). However, calculating the success rate from the putative number of blastocysts (computed from data in Table 2) showed no significant difference between donor cell types. For example, in the NSC experiments, 1072 two-cell embryos were transferred into uteri (Table 1), and 9.8\% of the two-cell embryos developed to blastocysts in vitro (Table 2) giving a putative number of 105 cloned blastocysts in vivo. Five cloned mice were born from these embryos, giving a success rate of $4.7 \%$. Using the same method to calculate the cloning efficiency, in terms of viable mice as a percentage of putative blastocysts for other cell types, gave values of $0 \%$ for differentiated NSCs, $3.7 \%$ for Sertoli cells, 3.8\% for cumulus cells, and $4.3 \%$ for ES cells. However, no cloned mice from differentiated NSCs survived. Comparing the birth rate of cloned mice of NSCs and differentiated NSCs in the same way, the birth rate was $4.7 \%$ for NSCs and $2.2 \%$ for differentiated NSCs, although these did not differ significantly. Although the cloning efficiency of the ES cells used in this study was lower, the characteristics, including the cloning efficiency, vary according to cell line, backgrounds, and other factors. We also succeeded in establishing ntES cell lines from cloned blastocysts derived from NSC nuclei $(60 \%$ or three ntES cell lines produced from five cloned blastocysts), and we obtained results similar to those reported for differentiated somatic cell nuclei (Wakayama et al. 2005b). These results suggest that blastocysts from NSCs are of the same quality as those of blastocysts cloned from other donor cells.

Improved animal cloning technology may allow us to produce gene-modified animals by homologous recombination in donor somatic cells (McCreath et al. 2000). The technique requires the proliferative ability of donor cells to select the clonal cell population that contains the modified target gene, and to be performed routinely in ES cells. In other animal species, where definitive ES cell 
lines do not exist, an anticipated alternative are the somatic stem cells. NSCs may be useful for gene targeting because they have high proliferative activity and the ability to develop to full term after nuclear transfer, as shown in this study. Neural precursor cells have been isolated from porcine brain (Schwartz et al. 2005). Thus, NSCs may provide an alternative source of cells, without the need for ES cells, to generate genemodified animals in other species.

\section{Acknowledgements}

We are grateful to the Laboratory for Animal Resources and Genetic Engineering of RIKEN-KOBE, Center for Developmental Biology for housing the mice. The authors declare that there is no conflict of interest that would prejudice the impartiality of this scientific work.

\section{References}

Alison M \& Sarraf C 1998 Hepatic stem cells. Journal of Hepatology 29 676-682.

Brazel CY, Romanko MJ, Rothstein RP \& Levison SW 2003 Roles of the mammalian subventricular zone in brain development. Progress in Neurobiology 69 49-69.

Cheong HT, Takahashi Y \& Kanagawa H 1993 Birth of mice after transplantation of early cell-cycle-stage embryonic nuclei into enucleated oocytes. Biology of Reproduction 48 958-963.

Debus E, Weber K \& Osborn M 1983 Monoclonal antibodies specific for glial fibrillary acidic (GFA) protein and for each of the neurofilament triplet polypeptides. Differentiation 25 193-203.

Duittoz AH \& Hevor T 2001 Primary culture of neural precursors from the ovine central nervous system (CNS). Journal of Neuroscience Methods 107 131-140.

Eggan K, Akutsu H, Loring J, Jackson-Grusby L, Klemm M, Rideout WM III, Yanagimachi R \& Jaenisch R 2001 Hybrid vigor, fetal overgrowth, and viability of mice derived by nuclear cloning and tetraploid embryo complementation. PNAS 98 6209-6214.

Eggan K, Baldwin K, Tackett M, Osborne J, Gogos J, Chess A, Axel R \& Jaenisch R 2004 Mice cloned from olfactory sensory neurons. Nature 428 44-49.

Fridenshtein A 1982 Stromal bone marrow cells and the hematopoietic microenvironment. Arkhiv Patologii 44 3-11.

Gage FH 2000 Mammalian neural stem cells. Science 287 1433-1438.

Hiiragi T \& Solter D 2005 Reprogramming is essential in nuclear transfer. Molecular Reproduction and Development 70 417-421.

Inoue K, Wakao H, Ogonuki N, Miki H, Seino K, Nambu-Wakao R, Noda S, Miyoshi H, Koseki H, Taniguchi M \& Ogura A 2005 Generation of cloned mice by direct nuclear transfer from natural killer T cells. Current Biology 15 1114-1118.

Inoue K, Ogonuki N, Miki H, Hirose M, Noda S, Kim JM, Aoki F, Miyoshi H \& Ogura A 2006 Inefficient reprogramming of the hematopoietic stem cell genome following nuclear transfer. Journal of Cell Science 119 1985-1991.

Jeanisch R, Eggan K, Humpherys D, Rideout W \& Hochedlinger K 2002 Nuclear cloning, stem cells, and genomic reprogramming. Cloning Stem Cells 4 389-396.

Jiang Y, Jahagirdar BN, Reinhardt RL, Schwartz RE, Keene CD, OrtizGonzalez XR, Reyes M, Lenvik T, Lund T, Blackstad M, Du J, Aldrich S, Lisberg A, Low WC, Largaespada DA \& Verfaillie CM 2002a Pluripotency of mesenchymal stem cells derived from adult marrow. Nature 418 41-49.
Jiang Y, Vaessen B, Lenvik T, Blackstad M, Reyes M \& Verfaillie CM 2002b Multipotent progenitor cells can be isolated from postnatal murine bone marrow, muscle, and brain. Experimental Hematology 30 896-904.

Kim M \& Morshead CM 2003 Distinct populations of forebrain neural stem and progenitor cells can be isolated using side-population analysis. Journal of Neuroscience 23 10703-10709.

Kishigami S, Mizutani E, Ohta H, Hikichi T, Thuan NV, Wakayama S, Bui HT \& Wakayama T 2006 Significant improvement of mouse cloning technique by treatment with trichostatin A after somatic nuclear transfer. Biochemical and Biophysical Research Communications 340 183-189.

Li J, Ishii T, Feinstein P \& Mombaerts P 2004 Odorant receptor gene choice is reset by nuclear transfer from mouse olfactory sensory neurons. Nature 428 393-399.

Ma J, Svoboda P, Schultz RM \& Stein P 2001 Regulation of zygotic gene activation in the preimplantation mouse embryo: global activation and repression of gene expression. Biology of Reproduction 64 1713-1721.

Makino H, Yamazaki Y, Hirabayashi T, Kaneko R, Hamada S, Kawamura Y, Osada T, Yanagimachi R \& Yagi T 2005 Mouse embryos and chimera cloned from neural cells in the postnatal cerebral cortex. Cloning Stem Cells 7 45-61.

McCreath KJ, Howcroft J, Campbell KH, Colman A, Schnieke AE \& Kind AJ 2000 Production of gene-targeted sheep by nuclear transfer from cultured somatic cells. Nature 405 1066-1069.

Nagy A, Gocza E, Diaz EM, Prideaux VR, Ivanyi E, Markkula M \& Rossant J 1990 Embryonic stem cells alone are able to support fetal development in the mouse. Development 110 815-821.

Oback B \& Wells D 2002 Donor cells for nuclear cloning: many are called, but few are chosen. Cloning Stem Cells 4 147-168.

Ogura A, Inoue K, Ogonuki N, Noguchi A, Takano K, Nagano R, Suzuki O, Lee J, Ishino F \& Matsuda J 2000 Production of male cloned mice from fresh, cultured, and cryopreserved immature Sertoli cells. Biology of Reproduction 62 1579-1584.

Peretto P, Merighi A, Fasolo A \& Bonfanti L 1999 The subependymal layer in rodents: a site of structural plasticity and cell migration in the adult mammalian brain. Brain Research Bulletin 49 221-243.

Potten CS 1998 Stem cells in gastrointestinal epithelium: numbers, characteristics and death. Philosophical Transactions of the Royal Society of London. Series B: Biological Sciences 353 821-830.

Reynolds BA \& Weiss S 1992 Generation of neurons and astrocytes from isolated cells of the adult mammalian central nervous system. Science 255 1707-1710.

Reynolds BA \& Weiss S 1996 Clonal and population analyses demonstrate that an EGF-responsive mammalian embryonic CNS precursor is a stem cell. Developmental Biology 175 1-13.

Rideout WM III, Wakayama T, Wutz A, Eggan K, Jackson-Grusby L, Dausman J, Yanagimachi R \& Jaenisch R 2000 Generation of mice from wild-type and targeted ES cells by nuclear cloning. Nature Genetics 24 109-110.

Schultz RM, Davis W Jr, Stein P \& Svoboda P 1999 Reprogramming of gene expression during preimplantation development. Journal of Experimental Zoology 285 276-282.

Schwartz PH, Nethercott H, Kirov II, Ziaeian B, Young MJ \& Klassen H 2005 Expression of neurodevelopmental markers by cultured porcine neural precursor cells. Stem Cells 23 1286-1294.

Sommer I \& Schachner M 1981 Monoclonal antibodies (O1 to O4) to oligodendrocyte cell surfaces: an immunocytological study in the central nervous system. Developmental Biology 83 311-327.

Sullivan KF 1988 Structure and utilization of tubulin isotypes. Annual Review of Cell Biology 4 687-716.

Wakayama T \& Yanagimachi R 1999 Cloning of male mice from adult tail-tip cells. Nature Genetics 22 127-128.

Wakayama T \& Yanagimachi R 2001 Effect of cytokinesis inhibitors, DMSO and the timing of oocyte activation on mouse cloning using cumulus cell nuclei. Reproduction 122 49-60. 
Wakayama T, Perry AC, Zuccotti M, Johnson KR \& Yanagimachi $R$ 1998 Full-term development of mice from enucleated oocytes injected with cumulus cell nuclei. Nature 394 369-374.

Wakayama T, Rodriguez I, Perry AC, Yanagimachi R \& Mombaerts P 1999 Mice cloned from embryonic stem cells. PNAS 96 14984-14989.

Wakayama T, Tabar V, Rodriguez I, Perry AC, Studer L \& Mombaerts P 2001 Differentiation of embryonic stem cell lines generated from adult somatic cells by nuclear transfer. Science 292 740-743.

Wakayama S, Cibelli JB \& Wakayama T 2003 Effect of timing of the removal of oocyte chromosomes before or after injection of somatic nucleus on development of NTembryos. Cloning Stem Cells 5 181-189.

Wakayama S, Mizutani E, Kishigami S, Thuan NV, Ohta H, Hikichi T, Bui HT, Miyake M \& Wakayama T 2005a Mice cloned by nuclear transfer from somatic and ntES cells derived from the same individuals. Journal of Reproduction and Development 51 765-772.

Wakayama S, Ohta H, Kishigami S, Thuan NV, Hikichi T, Mizutani E, Miyake M \& Wakayama T 2005b Establishment of male and female nuclear transfer embryonic stem cell lines from different mouse strains and tissues. Biology of Reproduction 72 932-936.
Watt FM 1998 Epidermal stem cells: markers, patterning and the control of stem cell fate. Philosophical Transactions of the Royal Society of London. Series B: Biological Sciences 353 831-837.

Weissman IL 2000 Translating stem and progenitor cell biology to the clinic: barriers and opportunities. Science 287 1442-1446.

Yamazaki Y, Makino H, Hamaguchi-Hamada K, Hamada S, Sugino H, Kawase E, Miyata T, Ogawa M, Yanagimachi R \& Yagi T 2001 Assessment of the developmental totipotency of neural cells in the cerebral cortex of mouse embryo by nuclear transfer. PNAS 98 14022-14026.

Zeng F \& Schultz RM 2005 RNA transcript profiling during zygotic gene activation in the preimplantation mouse embryo. Developmental Biology 283 40-57.

Received 19 October 2005

First decision 22 November 2005

Revised manuscript received 4 August 2006

Accepted 20 September 2006 